Article

\title{
High Electrochemical Performance of Nanotube Structured ZnS as Anode Material for Lithium-Ion Batteries
}

\author{
Wen Zhang ${ }^{1}$, Junfan Zhang ${ }^{1}$, Yan Zhao ${ }^{1, *}$, Taizhe Tan ${ }^{2}$ and Tai Yang ${ }^{1, *}$ (D) \\ 1 School of Materials Science and Engineering, Research Institute for Energy Equipment Materials, \\ Hebei University of Technology, Tianjin 300130, China; zhangwen@hebut.edu.cn (W.Z.); \\ 18722593259@163.com (J.Z.) \\ 2 Synergy Innovation Institute of GDUT, Heyuan 517000, Guangdong, China; tztansii18@163.com \\ * Correspondence: yanzhao1984@hebut.edu.cn (Y.Z.); yangtai999@163.com (T.Y.); Tel.: +86-22-6020-1433 (T.Y.)
}

Received: 3 July 2018; Accepted: 23 August 2018; Published: 26 August 2018

\begin{abstract}
By using $\mathrm{ZnO}$ nanorods as an ideal sacrificial template, one-dimensional (1-D) ZnS nanotubes with a mean diameter of $10 \mathrm{~nm}$ were successfully synthesized by hydrothermal method. The phase composition and microstructure of the $\mathrm{ZnS}$ nanotubes were characterized by using XRD (X-ray diffraction), SEM (scanning electron micrograph), and TEM (transmission electronic microscopy) analysis. X-ray photoelectron spectroscopy (XPS) and nitrogen sorption isotherms measurements were also used to study the information on the surface chemical compositions and specific surface area of the sample. The prepared $\mathrm{ZnS}$ nanotubes were used as anode materials in lithium-ion batteries. Results show that the $\mathrm{ZnS}$ nanotubes deliver an impressive prime discharge capacity as high as $950 \mathrm{mAh} / \mathrm{g}$. The ZnS nanotubes also exhibit an enhanced cyclic performance. Even after 100 charge/discharge cycles, the discharge capacity could still remain at $450 \mathrm{mAh} / \mathrm{g}$. Moreover, cyclic voltammetry (CV) and electrochemical impedance spectroscopy (EIS) measurements were also carried out to evaluate the $\mathrm{ZnS}$ electrodes.
\end{abstract}

Keywords: lithium-ion batteries; zinc sulfide; nanotubes; anode material; electrochemical performance

\section{Introduction}

In recent decades, lithium-ion batteries play an increasingly dominating role in portable electronic devices due to the fact that they have the advantages of long service life, high energy density, high reversible capacity, and environmental friendliness [1]. Graphitic materials as a conventional anode material in lithium-ion batteries are extensively used for their good electrochemical properties and their structural stability during charge-discharge cycling [2]. However, traditional graphitic carbon materials severely hinder the development of lithium-ion batteries due to their low theoretical capacity $(372 \mathrm{mAh} / \mathrm{g})[3,4]$. In order to meet energy storage needs, it is necessary to exploit new types of anode materials to replace carbon materials. Metal sulfides—such as $\mathrm{CuS}, \mathrm{MoS}_{2}, \mathrm{NiS}$, and ZnS-also have been used as anodic electrode materials in lithium-ion batteries [5-8]. For example, CuS/graphene composite have a good charge-discharge cycling performance; however, its initial discharge capacity was only $627 \mathrm{mAh} / \mathrm{g}$ [9]. NiS-carbon nanofiber films have worse electrochemical properties, and its discharge capacity decayed below $100 \mathrm{mAh} / \mathrm{g}$ after 40 cycles [10]. $\mathrm{MoS}_{2}$ nanowall/graphene has a stable discharge capacity of about $700 \mathrm{mAh} / \mathrm{g}$ [11], which is still unimpressive. ZnS, by contrast, is viewed as a very promising alternative to carbon anode material due to its high theoretical capacity (962.3 mAh/g) [12]. Unfortunately, some drawbacks hinder its commercialization process. The main problem is significant volume changes during its charging and discharging processes, which leads to a great capacity fade upon cycling [13]. Moreover, normal ZnS particles have poor electrical 
conductivity, as a result, anode electrodes made using unmodified ZnS suffer from a poor cyclic and rate performance [14].

There are two possible ways to solve above mentioned problems. For one thing, we should focus on the synthesis of nano-sized particles, which can effectively adapt to volume changes during the charge-discharge progress [15-17]. For another, it is an effective method to combine nano-structured $\mathrm{ZnS}$ particles with conductive carbon coating to increase conductivity of anodic materials in lithium-ion batteries [18]. He et al. [14] prepared ZnS/C composites by a combined precipitation with carbon coating method and applied them as anode material for lithium-ion batteries. Du et al. [12] also synthesized nanocrystalline $\mathrm{ZnS} / \mathrm{C}$ with core/shell structure by using a simple solvothermal process and an annealing process. These studies have made some progress in development of anodic materials for lithium-ion batteries. Nevertheless, the above-mentioned preparation methods of nanocrystalline $\mathrm{ZnS} / \mathrm{C}$ composites are complicated and costly. 1-D ZnS nanotubes also have been proved to be a promising candidate material $[19,20]$. It is well-known that active materials in anodes with large surface areas can increase the contact area between electrolyte and electrode materials, thereby enhancing energy storage density [21]. Moreover, nano-materials can also shorten the transport path of conductive ions, and the electrodes will not be destroyed even though a large volume change of $\mathrm{ZnS}$ occurs in the charge-discharge process [22,23]. It was reported that nanotubes can expand radially as well as longitudinally to mitigate the stress, which would make them more suitable for high rate applications [24].

In order to further investigate the electrochemical performance of nano-structured sulfides, $\mathrm{ZnS}$ nanotubes were prepared by hydrothermal method by using $\mathrm{ZnO}$ nanorod arrays as sacrificial template. The prepared $\mathrm{ZnS}$ nanotubes exhibit a well rate discharge performance. The discharge capacity of $\mathrm{ZnS}$ nanotubes is as high as $950 \mathrm{mAh} / \mathrm{g}$ in the first cycle, and it still remains at $450 \mathrm{mAh} / \mathrm{g}$ after 100 charge/discharge cycles.

\section{Materials and Methods}

\subsection{Synthesis of ZnS Samples}

Firstly, $25 \mathrm{mmol}$ of $\mathrm{Zn}\left(\mathrm{NO}_{3}\right)_{2} \cdot 6 \mathrm{H}_{2} \mathrm{O}$ and $50 \mathrm{~mL}$ of polyvinyl pyrrolidone (PVP) aqueous solution $(0.1 \mathrm{wt} \%)$ were mixed with a certain amount of deionized water to get $\mathrm{Zn}\left(\mathrm{NO}_{3}\right)_{2}$ solution of $0.05 \mathrm{~mol} / \mathrm{L}$. At the same time, hexamethylenetetramine $\left(\mathrm{C}_{6} \mathrm{H}_{12} \mathrm{~N}_{4}\right)$ solution $(50 \mathrm{~mL}, 0.1 \mathrm{wt} \%)$ was also prepared. Above two solutions were mixed, heated, and stirred in a beaker-flask at $90^{\circ} \mathrm{C}$ for $16 \mathrm{~h}$. Then the white products were collected and washed by deionized water and ethanol three times, and the precipitate was dried in a vacuum oven at $70{ }^{\circ} \mathrm{C}$ for $12 \mathrm{~h}$. Finally, pure $\mathrm{ZnO}$ nanorods were obtained.

Subsequently, the ZnS nanotubes were synthesized by hydrothermal method by using the ZnO nanorods as template. The prepared pure $\mathrm{ZnO}$ nanorods were dispersed in $20 \mathrm{~mL}$ of ethylene glycol $\left(\mathrm{C}_{2} \mathrm{H}_{6} \mathrm{O}_{2}\right)$ solution, stirring and sonicating for $20 \mathrm{~min}$. After that, thioacetamide $\left(\mathrm{CH}_{3} \mathrm{CSNH}_{2}\right)$ was dripped into the above-mentioned $\mathrm{ZnO}$ suspension. The mixture solution was transferred to a Teflon-lined stainless-steel autoclave and placed into an oven maintained at $145^{\circ} \mathrm{C}$ for $10 \mathrm{~h}$. After this reaction, the $\mathrm{ZnO} / \mathrm{ZnS}$ nano composites were collected and washed three times using deionized water and pure ethanol. Then, $2 \mathrm{~g}$ of $\mathrm{ZnO} / \mathrm{ZnS}$ nano composites were added into $50 \mathrm{~mL}$ of $10 \mathrm{M} \mathrm{NaOH}$ aqueous solution and stirred for $2 \mathrm{~h}$ at room temperature to remove $\mathrm{ZnO}$ cores. The products were collected and dried at $80^{\circ} \mathrm{C}$ for $10 \mathrm{~h}$, and then white $\mathrm{ZnS}$ nanotubes were obtained.

\subsection{Sample Characterizations}

XRD method was used to analyze the phase composition and crystal structure of the sample. The tests were performed at a scanning rate of $2^{\circ} / \mathrm{min}$ in the $2 \theta$ range from $20^{\circ}$ to $90^{\circ}$ by using an X-ray diffractometer (SmartLab Rigaku Corporation, Tokyo, Japan). Identification of the species was computer aided. The microstructure and corresponding selected area electron diffraction (SAED) patterns for the ZnS nanotubes were also performed by using SEM (Hitachi S-4800) and TEM (JEOL-2010). Nitrogen sorption isotherms and Brunauer-Emmett-Teller (BET) surface area were measured at $423 \mathrm{~K}$ with a 
V-Sorb 2800P analyzer (GAPP, Beijing, China). XPS (Thermo Fisher Scientific, Waltham, MA, USA) measurements were conducted to evaluate the chemical states of elements in the sample.

\subsection{Electrochemical Measurements}

The electrochemical behaviors of the ZnS nanotubes were characterized by using CR 2025 coin cell. In order to prepare working electrodes (anodic electrodes), a slurry was mixed by using $70 \mathrm{wt} \%$ of $\mathrm{ZnS}$ nanotube powder, $15 \mathrm{wt} \%$ of carbon black and $15 \mathrm{wt} \%$ of polyvinylidene fluoride. The mixture was grinded for $40 \mathrm{~min}$ and dissolved in N-methyl-2-pyrrolidone (NMP), and the obtained slurry with a thickness of $0.1 \mathrm{~mm}$ was blade cast onto $\mathrm{Cu}$ foil. Then the prepared electrode material was dried at $70^{\circ} \mathrm{C}$ for $12 \mathrm{~h}$. After that, the dried electrodes were punch into coins in an argon-filled (99.999\%) glove box. The ZnS loading amount of each electrode sheet was approximately $2.5 \mathrm{mg} / \mathrm{cm}^{2}$. Pure lithium metal foils were used as reference anode, and microporous polypropylene as a separator. The electrolyte was a solution of $1 \mathrm{~mol} / \mathrm{L} \mathrm{LiPF}_{6}$ in ethylene carbonate $\left(\mathrm{C}_{3} \mathrm{H}_{4} \mathrm{O}_{3}\right)$ and dimethyl carbonate $\left(\mathrm{C}_{3} \mathrm{H}_{6} \mathrm{O}_{3}\right)$ with a volume ratio of 1:1. The charging and discharging measurements and cycle life tests of the prepared coin cells were carried out by using a multichannel battery testing system (Neware BTS4000). Considering the theoretical capacity $(962.3 \mathrm{mAh} / \mathrm{g})$ of $\mathrm{ZnS}$ [12], the charge-discharge current density of $962.3 \mathrm{~mA} / \mathrm{g}$ was defied as $1 \mathrm{C}$. After the 100th charge-discharge cycle, the cells were dismantled to collect the anode materials. Then the anode materials were soaked in N-methyl-2-pyrrolidone (NMP) for $4 \mathrm{~h}$ to remove the binder and conductive agent. The phase structure and micro morphology of the collected $\mathrm{ZnS}$ nanotubes were also carried out by XRD and SEM. The charge-discharge voltage ranged from $0.05 \mathrm{~V}$ to $3.00 \mathrm{~V}$. CV curves for the first three cycles were performed by an electrochemical workstation (Princeton, Versa STAT 4) at a scan rate of $0.1 \mathrm{mV} / \mathrm{s}$ in a voltage range of 0.01-3.00 V. The EIS measurements were also performed by the same electrochemical workstation with a frequency range of $10 \mathrm{kHz}-10 \mathrm{mHz}$ with a small sinusoidal perturbation of $10 \mathrm{mV}$.

\section{Results and Discussion}

\subsection{Structural and Composition Characterization}

SEM and TEM analysis were used to clarify the fine microstructures and morphologies of the $\mathrm{ZnS}$ sample. Figure $1 \mathrm{a}, \mathrm{b}$ shows the SEM images of the $\mathrm{ZnS}$ nanotubes. It can be easily observed that the morphology of the $\mathrm{ZnS}$ sample is a kind of hollow micro tube, with the tube wall thickness of about $80 \mathrm{~nm}$ and the length was 1-2 $\mu \mathrm{m}$. Detailed structural information of the $\mathrm{ZnS}$ sample was further investigated by TEM, results are shown in Figure 1c,d. Clearly, the nanotubes have a rough surface. The SAED pattern confirms the existence of ZnS. The three bright ED patterns correspond to the (111), (220), and (311) lattice plane of ZnS. Moreover, it can be observed from the high-resolution image shown in Figure $1 \mathrm{~d}$ that the nanotubes are mainly composed of nanocrystals. This type of nanostructure contributes to the enhancement of electrochemical performance for the electrodes.

The XRD pattern of the synthesized ZnS nanotube sample and corresponding JCPDS data are shown in Figure 2a. Sharp diffraction peaks indicate good crystallinity of the sample. All of the diffraction peaks correspond well with the data of ZnS (JCPDS no. 65-0309). The three major diffraction peaks located at $2 \theta=28.5^{\circ}, 47.5^{\circ}$, and $56.3^{\circ}$ correspond to (111), (220), and (311) crystal planes of ZnS. In order to know actual surface area of the $\mathrm{ZnS}$ nanotubes, $\mathrm{N}_{2}$ adsorption and desorption isotherms are carried out, results are shown in Figure 2a. Type IV isotherm curve is observed with hysteresis loop at higher pressure, indicating a large number of meso-pores present in the sample [25]. The BET specific surface area of the sample was as high as $86.86 \mathrm{~m}^{2} / \mathrm{g}$. The XPS measurement was also conducted to obtain the information on the surface chemical compositions and the valence states of corresponding elements in the sample. From Figure 2c, it can be seen that the XPS spectra of $S 2 p$ was divided into two peaks centered at 163.1 and $162.0 \mathrm{eV}$, corresponding to $S 2 p_{1 / 2}$ and $S 2 p_{3 / 2}$ states [26]. Figure $2 d$ depicted the XPS spectrum of the Zn 2p peaks centered at 1044.2 and $1021.3 \mathrm{eV}$, which associated with $\mathrm{Cu} 2 \mathrm{p}_{1 / 2}$ and $\mathrm{Cu} 2 \mathrm{p}_{3 / 2}$, respectively [27]. 

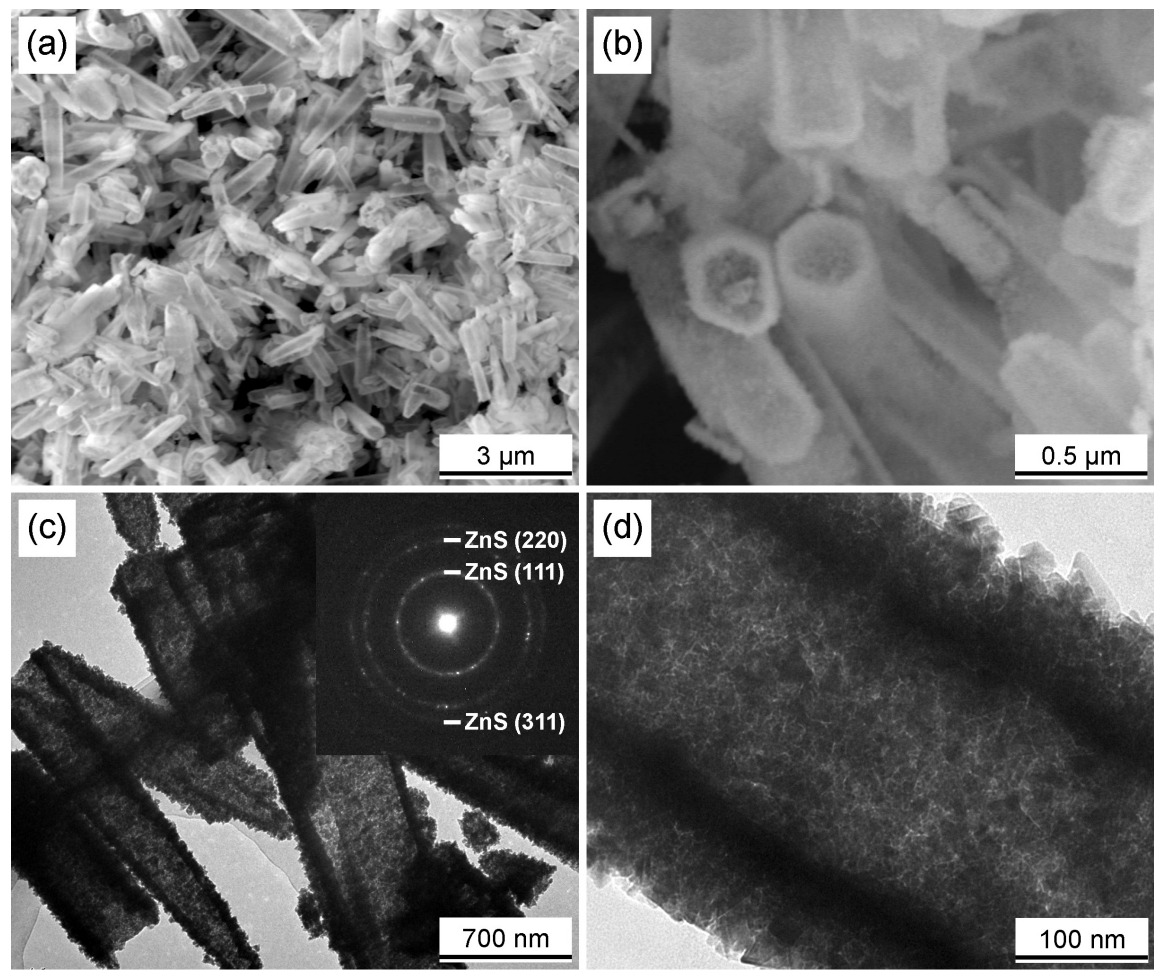

Figure 1. (a,b) SEM images of the prepared ZnS nanotubes; (c,d) TEM images together with corresponding SAED patterns of the $\mathrm{ZnS}$ nanotubes.
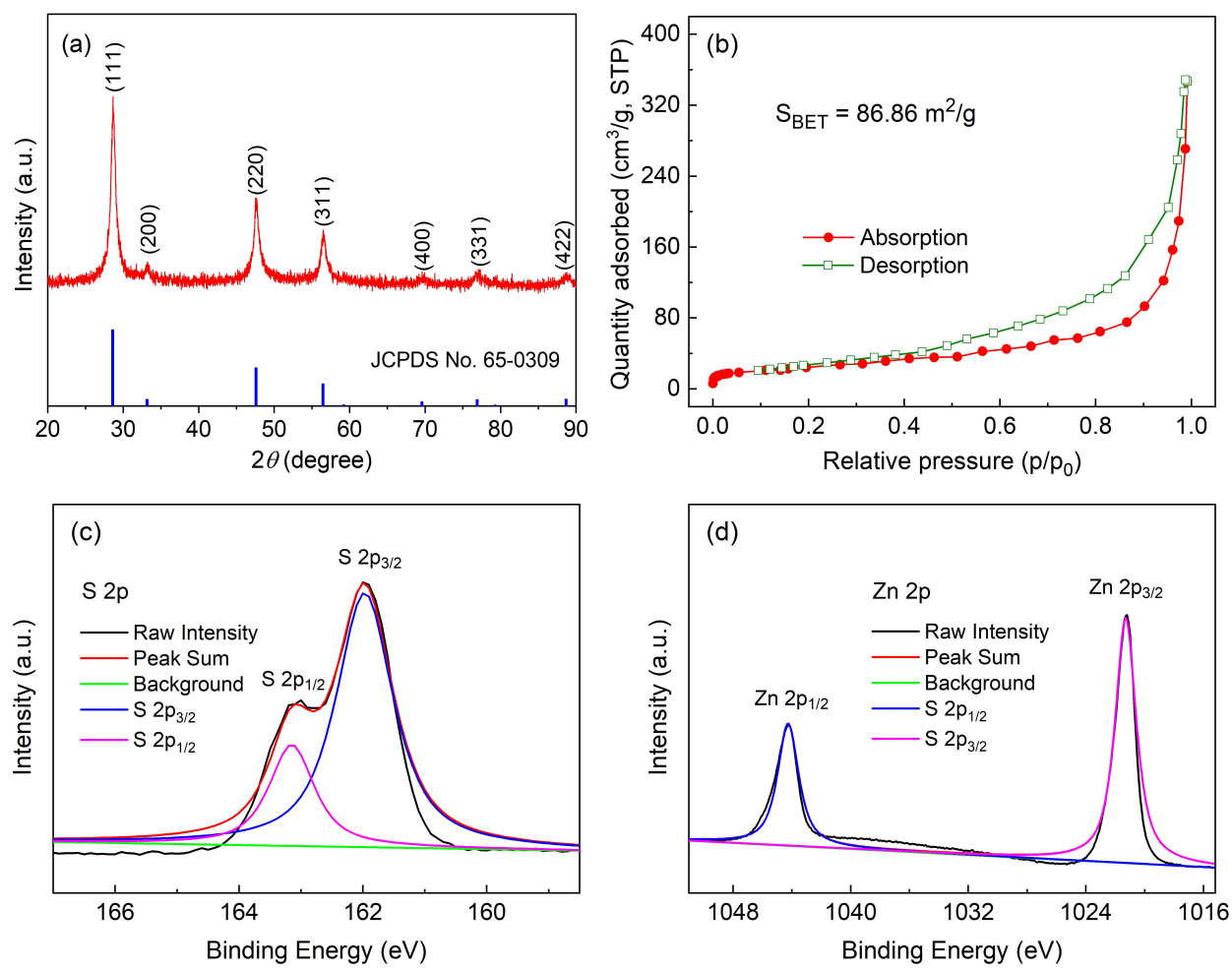

Figure 2. (a) XRD pattern of the $\mathrm{ZnS}$ nanotubes; (b) $\mathrm{N}_{2}$ adsorption-desorption isotherm of the $\mathrm{ZnS}$ nanotubes; (c,d) XPS analysis for the ZnS nanotubes. 


\subsection{Electrochemical Performance}

The discharge rate capabilities of the $\mathrm{ZnS}$ electrodes were tested at different current densities, as shown in Figure 3a. It can be observed that the discharge capacity of the ZnS electrode was steadily and has the high reversible capacities of $610,500,410$, and $320 \mathrm{mAh} / \mathrm{g}$ at the discharge current density of $0.2,0.5,1$, and $2 \mathrm{C}$. The specific capacity of the electrode is nearly recovered to its initial value in the case of the current density is goes back abruptly from $2 \mathrm{C}$ to $0.2 \mathrm{C}$, further proving good reversibility and excellent cycling stability of the $\mathrm{ZnS}$ nanotube electrodes. The good rate discharge performance of the $\mathrm{ZnS}$ nanotubes is mainly due to the shortened lithium-ion diffusion distance and enhanced structural stability of the unique nanotubular structure [28]. Moreover, the hollow tubular structure can greatly increase the surface area of the material, which increases contact area between electrolyte and $\mathrm{ZnS}$ electrode material [29].

The charge-discharge profiles of the ZnS electrodes were evaluated by using galvanostatic method at the current density of $0.2 \mathrm{C}$, as shown in Figure $3 \mathrm{~b}$. During the initial discharge process, a typical slope can be clearly seen when the voltage was higher than $0.5 \mathrm{~V}$. A major discharge voltage plateau can be observed at about $0.45 \mathrm{~V}$, which represents to the lithiation reaction of $\mathrm{ZnS}$ nanotubes [30]. In the next few cycles, several typical charge/discharge stages can be observed, which could be due to the electrochemical activation of the system and tend to be stable [31]. The capacity fade during the first cycle can be result from the decomposition of electrolyte, which leads to the redistribution of the active materials [32]. In the following charge-discharge process, the $\mathrm{ZnS}$ electrode exhibits the same curves, indicating that the $\mathrm{ZnS}$ electrode has become stable. According to He et al. [14], the lithium insertion/extraction mechanism of $\mathrm{ZnS}$ active electrode material can be expressed: $(x+2) \mathrm{Li}^{+}+\mathrm{ZnS}+(x+2) \mathrm{e}^{-} \leftrightarrow \mathrm{Li}_{2} \mathrm{~S}+\mathrm{Li}_{x} \mathrm{Zn}$.
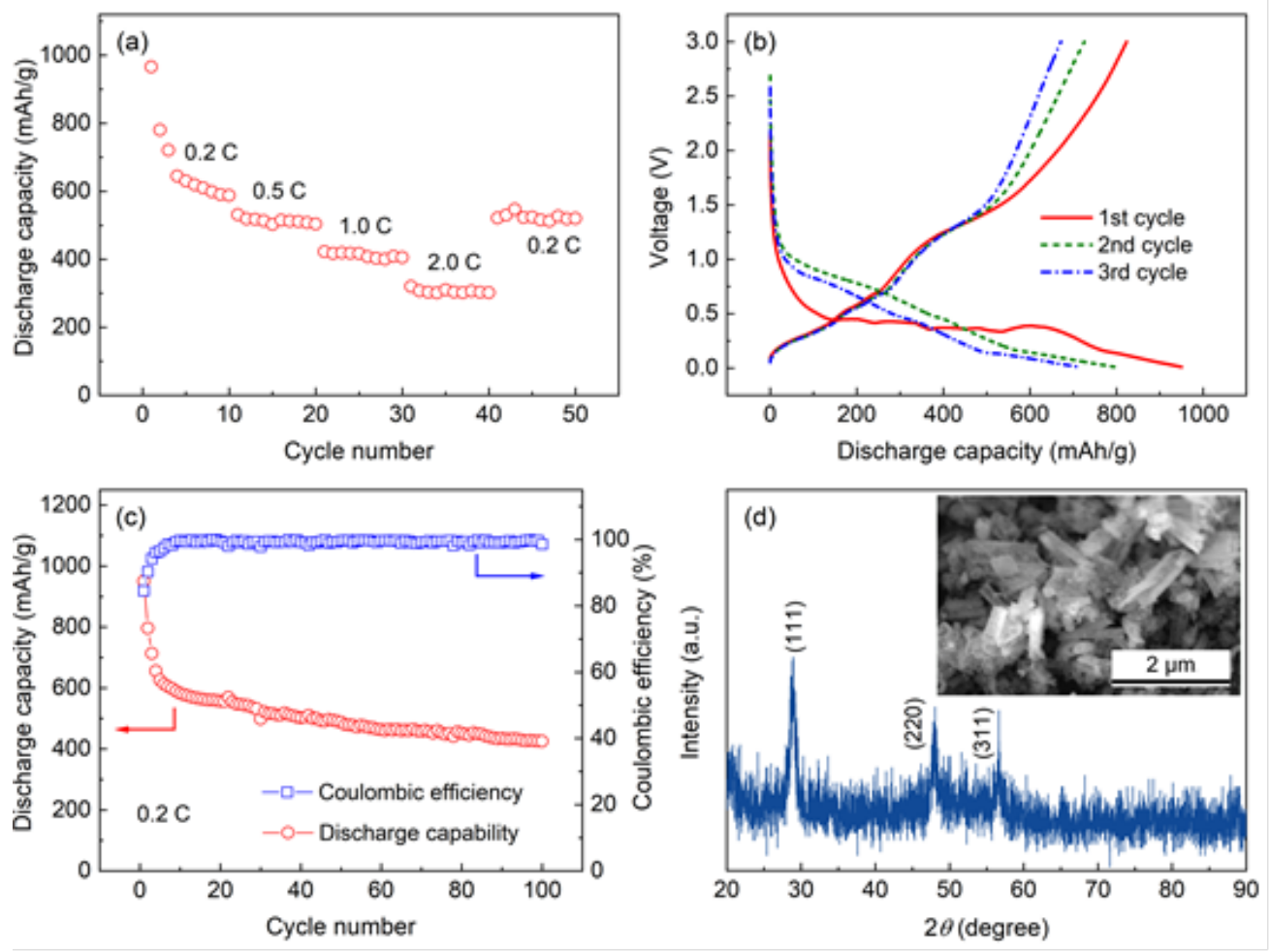

Figure 3. (a) Rate discharge capability of the ZnS electrodes together with the SEM images of ZnS nanotubes; (b) the first three galvanostatic charge/discharge profiles of the ZnS electrodes; (c) cycling performance and coulombic efficiency of the ZnS electrodes; (d) XRD pattern and SEM images of the ZnS nanotubes after 100th charge-discharge cycles. 
Figure $3 \mathrm{c}$ presents the cycling performance of the $\mathrm{ZnS}$ electrodes. It can be observed that it has an initial reversible discharge capacity of $950 \mathrm{mAh} / \mathrm{g}$ and its capacity keeps steady even after 100 cycles. In order to evaluate the charge-discharge efficiency, the coulombic efficiency of the electrodes was also exhibited in Figure 3c. The coulombic efficiency is defined as the percentage of discharge and charge capacity in one cycle. It is seen from Figure $3 c$ that the coulombic efficiency is almost $100 \%$ after about 10 cycles. Therefore, it can be concluded that the $\mathrm{ZnS}$ nanotube electrodes have a good cycling stability, meanwhile delivering a quite high reversible capacity. This is due to the fact that the ZnS nanotubes possess a large specific area, which provides more active sites for the lithium ions [33]. That is, during the charge or discharge processes, tube shaped $\mathrm{ZnS}$ can accommodate more lithium ions [33]. Moreover, 1-D ZnS nanotubes can shorten the lithium ion diffusion distance [34]. At the same time, nanotube structure has a beneficial effect on the volume expansion/shrinkage of ZnS during charge-discharge process [35]. The above reasons are why the $\mathrm{ZnS}$ nanotube electrodes have a good rate discharge capability and long cycle life.

In order to further investigate the structural changes of the ZnS nanotubes during chargedischarging process, the phase composition and microstructure for the $\mathrm{ZnS}$ nanotubes after 100 charge-discharge cycles were performed by using XRD and SEM. As shown in Figure 3d, three diffraction peaks can be clearly observed, which corresponds to the (111), (220), and (311) crystal. However, the intensity of the diffraction peaks is smaller than that of the prepared $\mathrm{ZnS}$ nanotubes before electrochemical cycle (Figure 2a). This may be due to the lower testing sample quantity. In addition, the SEM image of the sample after 100 charge-discharge cycles shows that the $\mathrm{ZnS}$ nanotubes still maintain a tube shape structure, together with some small amount of broken tube walls. Clearly, the $\mathrm{ZnS}$ nanotubes have a good structural stability during charge-discharge cycling, which leads to a good discharge capacity retention ratio.

Figure 4a shows the $\mathrm{CV}$ curves of the $\mathrm{ZnS}$ nanotube electrode at a scan rate of $0.1 \mathrm{mV} / \mathrm{s}$ between 0.01 to $3 \mathrm{~V}$ for the first, second, and third discharge/charge processes. In the first discharge process, two broad reduction peaks can be observed in the potential range of $1.1-0.25 \mathrm{~V}$ and $0.25-0.05 \mathrm{~V}$, respectively. The first reduction peak ranging from 1.1-0.25 V can be ascribed to the decomposition of ZnS into $\mathrm{Zn}$ and the formation of $\mathrm{Li}_{2} \mathrm{~S}$, while the second reduction peak ranging from $0.25-0.05 \mathrm{~V}$ corresponds to the subsequent reaction of lithium ions with Zn metal [14]. Decomposition of the electrolyte and formation of the solid electrolyte interface on the surface of electrode particles also occurs during the first cathodic cycle, which causes part of the irreversible capacity $[12,14]$. During the anodic scanning process, anodic peaks located at $0.28,0.37,0.57$, and $0.71 \mathrm{~V}$ are observed, which is attributed to the multi-step de-alloying process of $\mathrm{Li}-\mathrm{Zn}\left(\mathrm{LiZn}, \mathrm{Li}_{2} \mathrm{Zn}_{3}, \mathrm{LiZn}_{2}\right.$, and $\left.\mathrm{Li}_{2} \mathrm{Zn}_{5}\right)$ [12]. Another bigger anodic peak at $1.26 \mathrm{~V}$ is attributed to the back-conversion of $\mathrm{Zn}$ and $\mathrm{Li}_{2} \mathrm{~S}$ into $\mathrm{ZnS}[12,14]$. In the following cycles, the CV curves do not change position or intensity of any of the peaks, indicating that the $\mathrm{ZnS}$ nanotubes have a good reversibility.
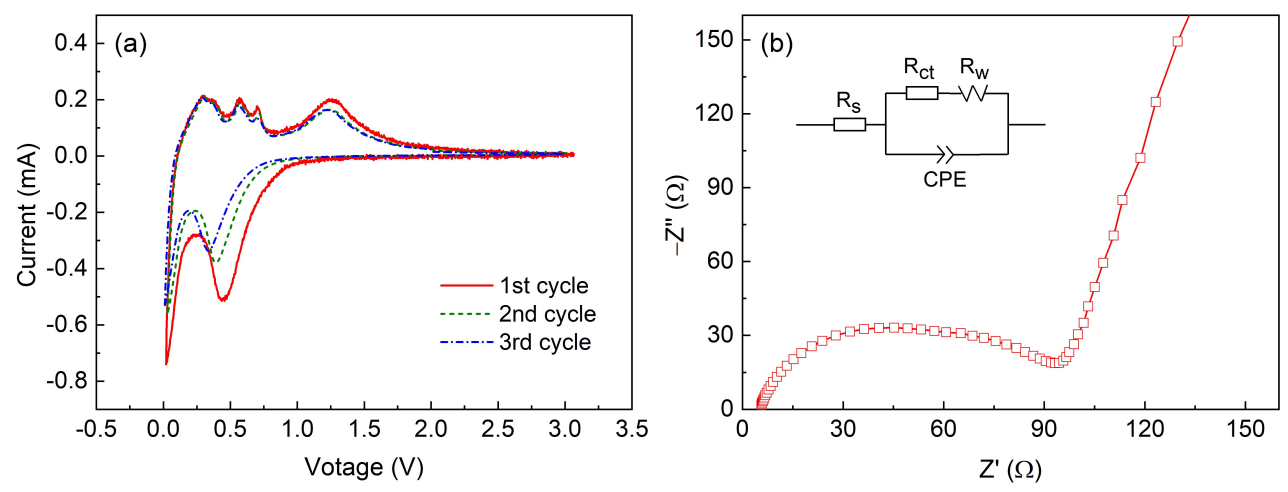

Figure 4. (a) CV curves of the $\mathrm{ZnS}$ nanotube electrode at a scan rate of $0.1 \mathrm{mV} / \mathrm{s}$; (b) Nyquist plots of the $\mathrm{ZnS}$ electrodes. 
To further confirm the electrochemical performance, the EIS studies of the $\mathrm{ZnS}$ nanotube electrodes were conducted, results are shown in Figure $4 \mathrm{~b}$. A semicircle and a slope line can be observed for both of the samples. As reported by Cheng et al. [36], the semicircles relate to the charge transfer resistance which resulted from charge transfer through the electrode/electrolyte interface, while the slope line corresponds to Warburg impedance over $\mathrm{Li}^{+}$diffusion in the solid materials. The impedance data were analyzed by fitting the curves with equivalent electrical circuit shown in the inset of Figure $4 \mathrm{~b}$, where $R_{\mathrm{s}}$ and $\mathrm{R}_{\mathrm{ct}}$ indicate electrolyte resistance and charge transfer resistance, respectively; CPE stands for the corresponding constant phase elements; and $R_{W}$ represents the diffusion-controlled Warburg impedance. The charge-transfer resistance of the as-synthesized $\mathrm{ZnS}$ nanotube electrodes is $88 \Omega$, which is much lower than the pure $\mathrm{ZnS}$ nanoparticles (199.5 $\Omega$ ) reported by Zhang et al. [37]. Moreover, the $\mathrm{ZnS}$ nanotube electrode has a higher slope, which means the $\mathrm{Li}^{+}$diffusion in the $\mathrm{ZnS}$ nanotubes is much faster than that of $\mathrm{ZnS}$ nanoparticles. Clearly, ZnS nanotube electrodes exhibit a good electrochemical performance.

\section{Conclusions}

Comprehensive analysis-using XRD, SEM, TEM, and XPS—indicates that the ZnS nanotubes were successfully prepared via a hydrothermal method. The BET specific surface area of the sample is as high as $86.86 \mathrm{~m}^{2} / \mathrm{g}$. The $\mathrm{ZnS}$ nanotube electrodes exhibit a good lithium ion storage capability. The first discharge capacity was about $950 \mathrm{mAh} / \mathrm{g}$, and it could still remain at $450 \mathrm{mAh} / \mathrm{g}$ after 100 charge/discharge cycles. This is due to the fact that the $\mathrm{ZnS}$ nanotubes have a good structural stability during charge-discharge cycling. In a word, this work provides a rational strategy to advance the $\mathrm{ZnS}$ anode electrochemical performance in lithium-ion batteries applications.

Author Contributions: Conceptualization, All authors; Methodology and experiment, W.Z., J.Z., and T.T.; Writing-Original Draft Preparation, W.Z. and J.Z.; Writing-Review \& Editing, Y.Z. and T.Y.; Funding Acquisition, W.Z. and T.Y.

Funding: This research was funded by Hebei Provincial Natural Science Foundation China [E2018202140] and Youth Top Talents Research Project of Hebei Provincial Education Department China [BJ2018036].

Conflicts of Interest: The authors declare no conflict of interest.

\section{References}

1. Li, H.P.; Li, Y.; Zhang, Y.G.; Zhang, C.W. Facile synthesis of carbon-coated $\mathrm{Fe}_{3} \mathrm{O}_{4}$ core-shell nanoparticles as anode materials for lithium-ion batteries. J. Nanopart. Res. 2015, 17, 370. [CrossRef]

2. Liu, Z.H.; Chai, J.C.; Xu, G.J.; Wang, Q.F.; Cui, G.L. Functional lithium borate salts and their potential application in high performance lithium batteries. Coord. Chem. Rev. 2015, 292, 56-73. [CrossRef]

3. Han, J.H.; Liu, P.; Ito, Y.; Guo, X.W.; Hiratai, A.; Fujita, T.; Chen, M.W. Bilayered nanoporous graphene/molybdenum oxide for high rate lithium ion batteries. Nano Energy 2018, 45, 273-279. [CrossRef]

4. Xu, J.M.; Han, Z.; Wu, J.S.; Song, K.X.; Wu, J.; Gao, H.F.; Mi, Y.H. Synthesis and electrochemical performance of vertical carbon nanotubes on few-layer graphene as an anode material for Li-ion batteries. Mater. Chem. Phys. 2018, 205, 359-365. [CrossRef]

5. Ren, Y.R.; Wei, H.M.; Yang, B.; Wang, J.W.; Ding, J.N. “Double-Sandwich-Like” CuS@reduced graphene oxide as an anode in lithium ion batteries with enhanced electrochemical performance. Electrochim. Acta 2014, 145, 193-200. [CrossRef]

6. Zhang, Y.G.; Li, Y.; Li, H.P.; Yin, F.X.; Zhao, Y.; Bakenov, Z. Synthesis of hierarchical $\mathrm{MoS}_{2}$ microspheres composed of nanosheets assembled via facile hydrothermal method as anode material for lithium-ion batteries. J. Nanopart. Res. 2016, 18, 1-9. [CrossRef]

7. Zhi, L.Z.; Han, E.S.; Cao, J.L. Synthesis and Characteristics of NiS for Cathode of Lithium Ion Batteries. Adv. Mater. Res. 2011, 236, 694-697. [CrossRef]

8. Mao, M.L.; Jiang, L.; Wu, L.C.; Zhang, M.; Wang, T.H. The structure control of ZnS/graphene composites and their excellent properties for lithium-ion battery. J. Mater. Chem. A 2015, 3, 13384-13389. [CrossRef] 
9. Li, H.; Wang, Y.H.; Huang, J.X.; Zhang, Y.Y.; Zhao, J.B. Microwave-assisted synthesis of CuS/graphene composite for enhanced lithium storage properties. Electrochim. Acta 2017, 225, 443-451. [CrossRef]

10. Li, X.; Chen, Y.; Zou, J.; Zeng, X.; Zhou, L.; Huang, H. Stable freestanding Li-ion battery cathodes by in situ conformal coating of conducting polypyrrole on NiS-carbon nanofiber films. J. Power Sources 2016, 331, 360-365. [CrossRef]

11. Guo, J.; Chen, X.; Jin, S.; Zhang, M.; Liang, C. Synthesis of graphene-like $\mathrm{MoS}_{2}$ nanowall/graphene nanosheethybrid materials with high lithium storage performance. Catal. Today 2015, 246, 165-171. [CrossRef]

12. Du, X.F.; Zhao, H.L.; Zhang, Z.J.; Lu, Y.; Gao, C.H.; Li, Z.L.; Teng, Y.Q.; Zhao, L.; Świerczek, K. Core-shell structured ZnS-C nanoparticles with enhanced electrochemical properties for high-performance lithium-ion batteries anodes. Electrochim. Acta 2017, 225, 129-136. [CrossRef]

13. Li, H.P.; Liu, Z.J.; Yang, S.; Zhao, Y.; Feng, Y.T.; Bakenov, Z.; Zhang, C.W.; Yin, F.X. Facile synthesis of ZnO nanoparticles on nitrogen-doped carbon nanotubes as high performance anode material for lithium-ion batteries. Materials 2017, 10, 1102. [CrossRef] [PubMed]

14. He, L.; Liao, X.Z.; Yang, K.; He, Y.S.; Wen, W.; Ma, Z.F. Electrochemical characteristics and intercalation mechanism of ZnS/C composite as anode active material for lithium-ion batteries. Electrochim. Acta 2011, 56, 1213-1218. [CrossRef]

15. Kim, I.; Kim, B.S.; Nam, S.; Lee, H.G.; Chung, H.K.; Cho, S.M.; Luu, T.H.T.; Hyun, S.; Kang, C. Cross-linked poly (vinylidene fluoride-co-hexafluoropropene) (PVDF-co-HFP) gel polymer electrolyte for flexible Li-ion battery integrated with organic light emitting diode (OLED). Materials 2018, 11, 543. [CrossRef] [PubMed]

16. Ma, J.J.; Wang, H.J.; Liu, X.; Liu, X.R.; Lu, L.D.; Nie, L.Y.; Yang, X.; Chai, Y.Q.; Yuan, R. Synthesis of tube shape $\mathrm{MnO} / \mathrm{C}$ composite from 3, 4, 9, 10-perylenetetracarboxylic dianhydride for lithium ion batteries. Chem. Eng. J. 2017, 309, 545-551. [CrossRef]

17. Xu, G.L.; Xu, Y.F.; Sun, H.; Fu, F.; Zheng, X.M.; Huang, L.; Li, J.T.; Yang, S.H.; Sun, S.G. Facile synthesis of porous $\mathrm{MnO} / \mathrm{C}$ nanotubes as a high capacity anode materialfor lithium ion batteries. Chem. Commun. 2012, 48, 8502-8504. [CrossRef] [PubMed]

18. Donne, A.L.; Jana, S.K.; Banerjee, S.; Basu, S.; Binetti, S. Optimized luminescence properties of Mn doped ZnS nanoparticles for photovoltaic applications. J. Appl. Phys. 2013, 113, 014903. [CrossRef]

19. Alvarez-Coronadoi, E.G.; González, L.A.; Rendón-Ángeles, J.C.; Meléndez-Lira, M.A.; Ramírez-Bon, R. Study of the structure and optical properties of $\mathrm{Cu}$ and $\mathrm{Mn}$ in situ doped $\mathrm{ZnS}$ films by chemical bath deposition. Mater. Sci. Semicond. Process. 2018, 81, 68-74. [CrossRef]

20. Liu, X.; Yang, Y.; Li, Q.; Wang, Z.Z.; Xing, X.X.; Wang, Y.D. Portably colorimetric paper sensor based on ZnS quantum dots for semi-quantitative detection of $\mathrm{Co}^{2+}$ through the measurement of grey level. Sens. Actuators B Chem. 2018, 260, 1068-1075. [CrossRef]

21. Reddy, A.L.M.; Shaijumon, M.M.; Gowda, S.R.; Ajayan, P.M. Coaxial $\mathrm{MnO}_{2}$ /carbon nanotube array electrodes for high-performance lithium batteries. Nano Lett. 2009, 9, 1002-1006. [CrossRef] [PubMed]

22. Yan, C.L.; Xue, D.F. Conversion of $\mathrm{ZnO}$ nanorod arrays into $\mathrm{ZnO} / \mathrm{ZnS}$ nanocable and $\mathrm{ZnS}$ nanotube arrays via an in situ chemistry strategy. J. Phys. Chem. B 2006, 110, 25850-25855. [CrossRef] [PubMed]

23. Wang, Y.S.; Ma, Z.M.; Chen, Y.J.; Zou, M.C.; Yousaf, M.; Yang, Y.B.; Yang, L.S.; Cao, A.Y.; Han, R.P.S. Controlled synthesis of core-shell carbon@ $\mathrm{MoS}_{2}$ nanotube sponges as high-performance battery electrodes. Adv. Mater. 2016, 28, 10175-10181. [CrossRef] [PubMed]

24. Chen, J.J. Recent Progress in Advanced Materials for Lithium ion Batteries. Materials 2013, 6, $156-183$. [CrossRef] [PubMed]

25. Pujari, R.B.; Lokhande, A.C.; Yadav, A.A.; Kim, J.H.; Lokhande, C.D. Synthesis of MnS microfibers for high performance flexible supercapacitors. Mater. Des. 2016, 108, 510-517. [CrossRef]

26. Ding, C.H.; Su, D.Z.; Ma, W.X.; Zhao, Y.J.; Yan, D.; Li, J.B.; Jin, H.B. Design of hierarchical CuS/graphene architectures with enhanced lithium storage capability. Appl. Surf. Sci. 2017, 403, 1-8. [CrossRef]

27. Wei, B.B.; Liang, H.F.; Wang, R.R.; Zhang, D.F.; Qi, Z.B.; Wang, Z.C. One-step synthesis of graphitic- $\mathrm{C}_{3} \mathrm{~N}_{4} / \mathrm{ZnS}$ composites for enhanced supercapacitor performance. J. Energy Chem. 2018, 27, 472-477. [CrossRef]

28. Chang, Y.C. Complex $\mathrm{ZnO} / \mathrm{ZnS}$ nanocable and nanotube arrays with high performance photocatalytic activity. J. Alloy. Compd. 2016, 664, 538-546. [CrossRef] 
29. Park, A.R.; Jeon, K.J.; Park, C.M. Electrochemical mechanism of Li insertion/extraction in ZnS and ZnS/C anodes for Li-ion batteries. Electrochim. Acta 2018, 265, 107-114. [CrossRef]

30. Saha, S.; Sarkar, P. Electronic structure of ZnO/ZnS core/shell quantum dots. Chem. Phys. Lett. 2013, 555, 191-195. [CrossRef]

31. Kaplan, H.K.; Sarsıcı, S.; Akay, S.K.; Ahmetoglu, M. The characteristics of ZnS/Si heterojunction diode fabricated bythermionic vacuum arc. J. Alloy. Compd. 2017, 724, 543-548. [CrossRef]

32. Cui, L.F.; Hu, L.B.; Choi, J.W.; Cui, Y. Light-weight free-standing carbon nanotube-silicon films for anodes of lithium ion batteries. ACS Nano 2010, 4, 3671-3678. [CrossRef] [PubMed]

33. Renuga, V.; Mohan, C.N.; Manikandan, A. Influence of $\mathrm{Mn}^{2+}$ ions on both core/shell of CuInS $2 / \mathrm{ZnS}^{2}$ nanocrystals. Mater. Res. Bull. 2018, 98, 265-274. [CrossRef]

34. Qin, W.; Li, D.S.; Zhang, X.J.; Yan, D.; Hu, B.W.; Pan, L.K. ZnS nanoparticles embedded in reduced graphene oxide as high performance anode material of sodium-ion batteries. Electrochim. Acta 2016, 191, 435-443. [CrossRef]

35. Ortiz, G.F.; Hanzu, I.; Lavela, P.; Knauth, P.; Djenizian, T.; José, N.A.; Tirado, J. Novel fabrication technologies of $1 \mathrm{D} \mathrm{TiO}_{2}$ nanotubes vertical tin and iron-based nanowires for Li-ion microbatteries. Int. J. Nanotechnol. 2012, 9, 260-294. [CrossRef]

36. Cheng, S.Y.; Shi, T.L.; Tao, X.X.; Zhong, Y.; Huang, Y.Y.; Li, J.J.; Liao, G.L.; Tang, Z.R. In-situ oxidized copper-based hybrid film on carbon cloth as flexible anode for high performance lithium-ion batteries. Electrochim. Acta 2016, 212, 492-499. [CrossRef]

37. Zhang, R.P.; Wang, Y.; Jia, M.Q.; Xu, J.J.; Pan, E. One-pot hydrothermal synthesis of ZnS quantum dots/graphene hybrids as a dual anode for sodium ion and lithium ion batteries. Appl. Surf. Sci. 2018, 437, 375-383. [CrossRef]

(C) 2018 by the authors. Licensee MDPI, Basel, Switzerland. This article is an open access article distributed under the terms and conditions of the Creative Commons Attribution (CC BY) license (http:/ / creativecommons.org/licenses/by/4.0/). 